\title{
Optimization of economic and environmental factors of the logistic system of enterprise management
}

\author{
Vasyl Porokhnya ${ }^{1, *}$, Yuriy Shertennikov ${ }^{2}$, Roman $_{\text {Ivanov }}^{2}$, and Oleksandr Ostapenko ${ }^{3}$ \\ ${ }^{1}$ Classical private university, Zaporizhzhia, 69061, Ukraine \\ ${ }^{2}$ Oles Honchar Dnipro National University, Dnipro, 49000, Ukraine \\ ${ }^{3}$ Taras Shevchenko National University of Kyiv, Military Institute, Kyiv, 03189, Ukraine
}

\begin{abstract}
The purpose of the study is to develop an economic-mathematical model of the socio-economic system, which takes into account its logistical structure and ecological viability. This allows for optimal budget planning for the new project. The methodology of the study is based on the method of J. Forster, who proposed to consider the logistics system of any enterprise as a system of reservoirs linked by material, financial and information flows. The main result of the study is as follows. The methodology is designed and developed a mathematical program that allows estimating the relative value of fixed assets of production and the number of costs for creating a retail network with the impact of the environmental components. It is shown that this ratio is determined by the value of all key parameters of the enterprise logistics system. This result was obtained through careful modeling of structural changes in the logistics system of the enterprise. All basic communications (flows) between the elements of the logistics system were also considered. Calculations were conducted for the system of the equations which have been written down in shape with discrete-time. At the same time modeling was carried out so that there were no "not physical" phenomena (such as overflow of warehouses, etc.). As a result of calculations, optimum values for all basic characteristics of the new project have been specified. The most actual has separately been considered for practice as a case of optimum planning of storage facilities. The practical importance of research consists that scientific representations about interrelation of the capacity of the enterprise with key parameters of the logistic system can form a basis for more effective planning and management budgetary and production processes at the enterprise, namely: it is more reasonable to plan scales of production and expenses on logistics creation.
\end{abstract}

\section{Introduction}

Despite the extensive literature on designing and management of logistic systems (LS) [1-11] in the scientific literature shortage of models which would describe all links LS within the limits of uniform system of the equations is felt. General difficulties arise with identification of models. Shortage of the information leads to essential errors in the justification of models. Articles $[1,2]$ provide the literary review in the discrete modelling of events describing a difficult supply chain. Models allow to study dynamics of a supply chain, to develop and compare alternative strategy.

Work [3] marks now the global and expanded markets should process and manage more and more differentiated products, with shorter life cycles, and consumer delivery periods are reduced by low volumes.

The requirement for more careful management of LS increases in such conditions [4]. Models LS should be created for this purpose [5-7]; it is necessary to consider factors of destabilization which reduce reliability, stability and efficiency of logistic processes [8-10]. The author of work [11] confirms risks of supply and demand it is necessary to consider.

Article of authors [12] offers model which, from the moment of representation, meets established to requirements. This model allows taking into consideration detailed features of the market. But at the same time, the model has a lack; it leads to stable solution in a broad range of parameters.

Authors Y. Sherstennikov and T. Rudjanova [13] have offered a method to eliminate this defect. This method is based on averaging of rates of sales and transportations of the goods on a certain time distance. Till now there are no effective methods to plan an advertising campaign in real time of the enterprise, in view of logistics of the enterprise and a market demand for products.

The purpose of develop economic-mathematical model of LS the enterprises for tasks of optimization of new projects and management the LS.

The researchers conducted before [1-12] studied only some certain functions of the LS. The presented approach differs that it covers all chain from production

\footnotetext{
${ }^{*}$ Corresponding author: vprhnp76@gmail.com
} 
to delivery to an ultimate consumer. The paper [13] is not considered the ecological viability.

\section{Presentation of the basic research}

The basic results of research. Investors plan to create the new enterprise with a complete cycle from production of the goods before delivery of the goods to the consumer. The scheme enterprise logistics should correspond to the scheme presented in Fig. 1.

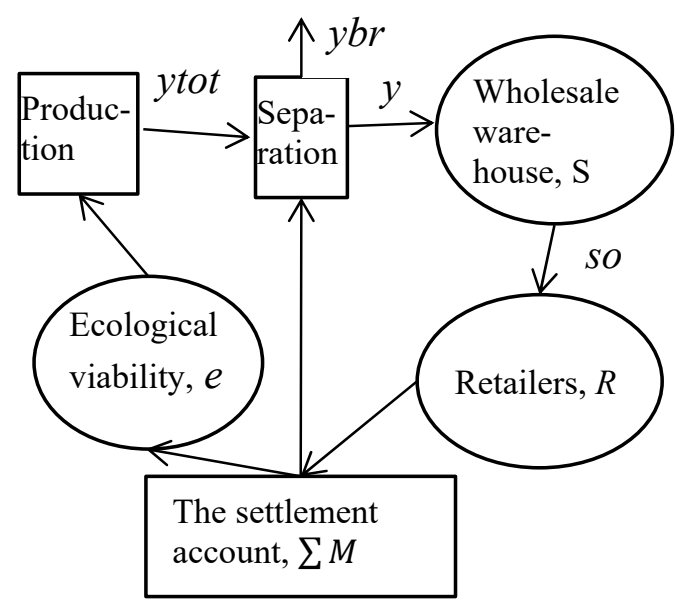

Fig. 1. Scheme of the enterprise's logistics.

It is supposed that the enterprise will be completely provided by raw and circulating assets.

Investors give the task to managers to calculate optimum parameters of all links of the LS when known technological parameters of production.

Time will be treated as a discrete variable $i$ $(i=0,1,2, \ldots, T)$. We will analyze the project of the $T$ length (the planning horizon). Let us assume that the influence of advertising on the potential current demand $Q_{i+1}$ in the $(i+1)^{\text {th }}$ period is described by the formula:

$$
Q_{i+1}=Q r(Z) *\left(1-\exp \left\{-\frac{i}{t}\right\}\right)+Q n(p),
$$

where $Q n(p)$ represents the value of potential demand that depends on the price for the product $(p)$ in the absence of advertising; $Q r(Z)=Q m *\left(1-\exp \left\{-\frac{Z}{t z}\right\}\right)$ is the maximum value of additional potential demand due to advertising; $t$ and $t z$ are the parameters of lagging; $Z$ - number of advertising shares in a current of one period (day).

Formula (1) means that the impact of the advertising campaign $Q_{i}$ on the potential demand is described by the first-order lag model $[7,8]$. In the absence of advertising, the potential demand for the product is determined only by its price $Q n(p)$.

We suggest the linear dependence of the impact of advertising $Q n(p)$ on the price:

$$
Q n(p)=Q n+k q *(p 0-p)
$$

where $Q n$ is the value of the potential demand at the price $p 0$.
Let us formulate the system of equations that describe the logistics system of the enterprise depicted in Figure 1. We will assume that the company is fully provided with working capital.

1. The change in the demand $Q_{i}$ for products on the market is an input impact for the enterprise whose task is to bring its output in line with the demand.

$$
r_{i+1}=n \cdot R_{i} \cdot\left(Q_{i}-V_{i}\right)
$$

where $n$ is the sales rate of goods (units per time period) in the $i^{\text {th }}$ period; $R_{i}$ is the inventory level (quantity od goods) at the retail in the $i^{\text {th }}$ period; $V_{i}$ is the inventory level in the hands of the consumer (not consumed yet).

2. Quantity of goods (inventory level - using the terminology of J. Forrester) at the retail $R_{i}$ is determined by the recurrence formula:

$$
R_{i+1}=R_{i}+T d \cdot\left(s o_{i}-r_{i}\right)
$$

where $s o_{i}$ is the rate of delivery (units per week) from the warehouse to retailers; $T d$ is the period of discretization of the model (the time interval between solution).

3. The level $R_{i}$ should be within the limits $0 \leq R_{i} \leq R m 0$, where $R m 0$ is the maximum possible inventory level at the retail. The requirement is described by the following formula for the rate of delivery from the wholesale warehouse to retailers:

$$
s o_{i+1}=\min \left[r_{i} \cdot\left(1+\frac{R m 0-R_{i}}{R m 0}\right), \frac{R m 0-R_{i}}{T d}, \frac{S_{i}}{T d}\right],
$$

where $S_{i}$ represents the inventory level at the wholesale warehouse.

Publication [5] substantiates the need for averaging in performing the calculations with the proposed model:

$$
\overline{S o}_{i}=\langle s o\rangle_{i-p s}^{i},
$$

where $p s$ is the averaging time interval.

4. The production rate $y_{i}$ is determined by the following formulas:

$$
\begin{aligned}
& y_{i+1}=\left(y_{i}+\frac{y m-y_{i}}{t y}\right) \cdot A\left(S_{i}\right), \\
& A\left(S_{i}\right)= \begin{cases}1, \text { if } S_{i}<q S \cdot S_{m} \\
\frac{q S \cdot S_{m}}{S_{i}} & \text { otherwise, }\end{cases}
\end{aligned}
$$

where $y_{i}$ is the production capacity in the $i^{\text {th }}$ period; $y m$ is the planned value of production capacity; $S m$ is the maximum inventory level at the wholesale warehouse. These formulas allow avoiding the overflow of the wholesale warehouse.

Planned the production capacity $y m$ is determined by balance cost of the basic production means (BPM) K, which can be presented in the form of the sum such composed $\mathrm{K}=\mathrm{K}^{(\mathrm{dc})}+\mathrm{K}^{(\mathrm{mr})}+\mathrm{K}^{(\mathrm{e})}$, where $\mathrm{K}^{(\mathrm{dc})}$ is BPM on which a damage control is producing, $\mathrm{K}^{(\mathrm{mr})}$ is BPM not corresponding modern safety requirements of ability to live and them need to replace; $\mathrm{K}^{(\mathrm{e})}$ is effectively used BPM. Thus, it is possible to write down: 
$y m=f \cdot K^{(e)}=e \cdot f \cdot K \quad(f$ is capital productivity $)$ where the parameter $e$ determines a share of BPM, which effectively used $(0<e<1)$. We will notice that damage control, and also current modernization of the equipment is carried out at the expense of money funds from the enterprise current account (see Fig. 1).

5. The inventory level at the wholesale warehouse $S_{i}$ is calculated using the following formula:

$$
S_{i+1}=S_{i}+T d *\left(y_{i}-s o_{i}\right),
$$

where $y_{i}$ is the rate of goods flow which goes into the wholesale warehouse from the production.

6 . To determine the net profit of the enterprise, the following formula is applied:

$$
\begin{gathered}
M_{i}=(1-k p) \cdot\left[(1-k a d) \cdot p \cdot r_{i}-p \cdot c \cdot y_{i}-\right. \\
\left.-k 2 \cdot S_{i}-z \cdot R m-q z \cdot Z\right]-B\left(y_{i}\right)+C\left(S_{i}\right), \\
B\left(y_{i}\right)=\left\{\begin{array}{c}
0, \text { if } i,<1 \\
q y\left|y_{i}-y_{i-1}\right|, \text { otherwise }
\end{array}\right.
\end{gathered}
$$

where $c$ is the share of the prime cost in the price for products; $p$ is the price for a production unit; $k 2$ is payment per one period of the storage of a product unit at the wholesale warehouse; $k p$ is the income tax rate; $k a d$ is the value-added tax rate; $q y$ is the cost of 'including', 'excluding' a unit of production capacity, $\mathrm{qz}$ is a cost of one advertising share.

The formula (9) provides inadmissibility of overflow of a wholesale warehouse. Composed it is added with that end in view. These are modelling "penal sanctions" for overflow wholesale warehouse:

$$
C\left(S_{i}\right)=\left\{\begin{array}{l}
o, \text { if } S_{i}<S m \\
-S_{s t}, \quad \text { otherwise }
\end{array},\right.
$$

\section{Construction of the investments plan}

Investors (the administration also) plan to create the new enterprise having for this purpose the budget at a rate of monetary units. All means it is planned to spend on two articles: acquisition of the basic production means (B1) and creation of a retail network of trade (B2). Premises for a wholesale warehouse are supposed to be leased. Carrying out of a permanent advertising campaign is planned also, but means for an advertising campaign should be allocated from current profit. Thus:

$$
B=B 1+B 2 .
$$

Expected life expectancy of the project is $T$. Then it is possible to write down such ratio

$$
p \cdot \sum_{i=1}^{T} y_{i}=f \cdot B 1,
$$

where $f$ is capital productivity from the project, for profitable projects $f$ is within the framework $(2 ; 4)$ (the top limit is an optimistic estimation).

For an estimation of planned capacity (productivity) $y m$ of the enterprise it is possible to use the approached formula $-\sum_{i=1}^{T} y_{i}=T \cdot y m$, then from the formula (11) it is found

$$
y m=\frac{f \cdot B 1}{p \cdot T} .
$$

At planning the retail managers of the enterprise recognize that at creation of areas the retail for placing of one commodity unit it is necessary to spend (on the average) $g$ monetary units. Then allocated budget will be enough for placing in shops the retail

$$
R m=\frac{B 2}{g} \text { (commodity units). }
$$

Here is maximum capacity of the retail. As variation parameter will be $B 1$, that $R m$ is actually defined from a relation:

$$
R m=\frac{B-B 1}{g} .
$$

Let's solve following tasks consistently.

Task A): at a preset value of the price $p$ of a commodity unit and in the absence of an advertising campaign $(Z=0)$ to find cost of the basic production means $(B 1)$ at which the maximum profit on the project will be got:

$$
F 1(B 1)=\sum_{i=0}^{T} M_{i} \rightarrow \max .
$$

Task B): considering parameter $p$ as variation in the absence of an advertising campaign, we must find cost of the basic industrial means $(B 1)$ and of the goods price at which the maximum profit on the project will be got:

$$
F 1(B 1, p)=\sum_{i=0}^{T} M_{i} \rightarrow \max .
$$

Task C): as variation parameters it is accepted both the commodity unit price $p$, and quantity of daily advertising shares $Z$ (which it is considered to constants). Thus, the mathematical task of optimization of the project is formulated as

$$
F 1(B 1, p, Z)=\sum_{i=0}^{T} M_{i} \rightarrow \max .
$$

Restrictions for tasks (15) - (17) there are both the equations of model (1) - (8) and an obvious condition:

$$
0 \leq B 1 \leq B
$$

We choose such units of measure. As a monetary unit, it is accepted a hundred dollars US (100 USD). Levels we will measure in units (quantity of the goods/raw materials), for rates we use the unit (quantity of the goods/raw materials per day).

The solution of problems (15) - (17), at the specified restrictions, we search at following values of technological parameters (the parameters of model):

$$
\begin{aligned}
& t=10, Q m=2000, z y=20, t z=30, k q=100, \\
& p 0=48, q S=0,88, n=1,6 * 10^{-5}, T d=1, \\
& k p=0,3, k a d=0,06, c=0,5, k 2=0,03 \\
& z=0,05, q z=0,6, q y=100, f=3, T=365, \\
& g=150, S_{s t}=1500
\end{aligned}
$$

Fig. 2 illustrates the optimum solution of C) problem. 
The solution of an optimizing task (15) it has been found at such values of the fixed parameters: $p=50$, $Z=0$ i.e. the price of goods is 50 monetary units; advertising was considered as the absent. At the solution of an optimizing task (16) advertising also was considered as the absent. Solution of the tasks of optimizing (15) - (17) it is then possible to present in the form of the table 1 .

Complete profit $\mathrm{F} 1$ for a year as function:

$\mathrm{B} 1 \mathrm{r}$ - cost of the basic production means; $\mathrm{pr}$ - goods price;

$\mathrm{Zr}$ - cost for the advertising campaign.

$$
\text { F1(B1r } \left.\mathrm{B}_{\mathrm{k}}, \mathrm{p}, \mathrm{Z}\right) \underbrace{2.5 \times 10^{4}}_{2 \times 10^{4}}
$$
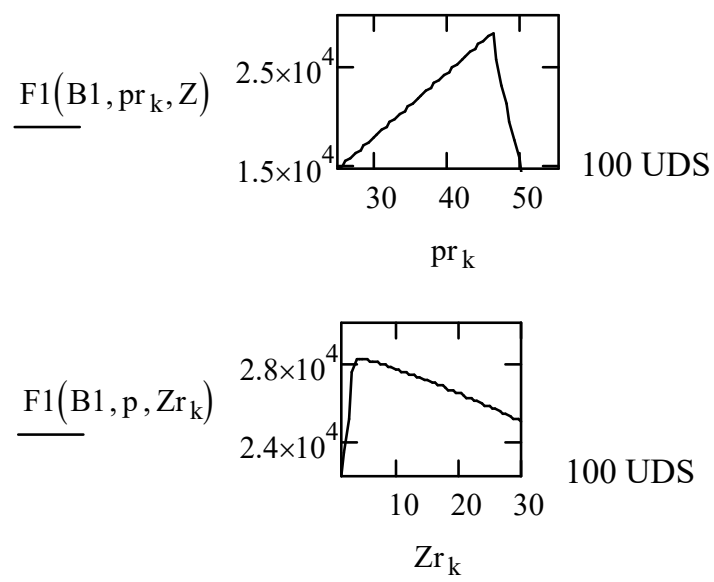

Fig. 2. An illustration of the optimum solution of problem C).

Table 1. Parameters of optimum solutions.

\begin{tabular}{|c|c|c|c|c|c|c|}
\hline Problem & $\boldsymbol{B 1}$ & $\boldsymbol{p}$ & $\boldsymbol{Z}$ & $\boldsymbol{y m}$ & $\boldsymbol{R m}$ & $\boldsymbol{F 1}$ \\
\hline A) & 25011 & 50 & 0 & 4,28 & 99,9 & 21239 \\
\hline $\mathrm{B})$ & 32429 & 45 & 0 & 5,55 & 50,5 & 27313 \\
\hline C) & 32954 & 46,2 & 3 & 5,64 & 46,97 & 28113 \\
\hline
\end{tabular}

From the table it is visible that at increase in number of variation parameters the economic result $F 1$ of the project increases. This result is quite natural.

Let's analyze an optimum solution of C) problem. Considering that for optimum a problem C) solution is $B 1=32954$, from formulas (12) and (14) it is discovered

$$
y m=5,64, R m=46,97
$$

Relations (12) and (14) solve a problem of definition of best values of key parameters of logistics system at the set budget $\left(B=4 * 10^{4}\right)$, namely: the basic industrial need to be spent means for acquisition $B 1=32954$; the retail it is necessary to spend for creation $B 2=7046$. Thus, optimum capacity will be $y m=5,64$, optimum capacity of the retail will be $R m=46,97$, the optimum price of a commodity unit will make $p=46,2$ (see table 1), optimum intensity of an advertising campaign will make $Z=3$ (actions per day).

\section{Optimization of logistics system of the enterprise}

Planning the price policy taking into account association of demand on the price of the goods, a management guarantees with managers to solve the following optimizing problem. As target function of a problem of optimization, the profit which will be received for planned time of life $T$ (the planning horizon) of project is chosen:

$$
F_{T}(y m, p, R m, S m, Z)=\sum_{i=1}^{T} M_{i} \rightarrow \max .
$$

Variation parameters of an optimizing problem (20) are: maximum productivity $y m$, the goods price $p$, maximum capacity $R m$ of a web of retail trade, maximum capacity of a wholesale warehouse $\mathrm{Sm}$ and a publicity expense $Z$. System of restrictions for an optimizing problem (20) is the set of equations (1) - (8). All enumerated parameters are included into system of the interconnected equations (1) - (8) which describe functioning of the LS of the enterprise. Therefore best value of these parameters should be received within the framework of one optimizing problem.

Optimizing problem (20) it is solved at following values of parameters:

$$
\begin{aligned}
& R m=80, \quad q y=100, \quad \mathrm{Q}=1200, \mathrm{n}=0.0001, \\
& \mathrm{k} 1=0.33, \quad k 2=0,01, \quad S o=100, S m=200, \\
& R o=50, n 1=0,1, \quad q S=0,88, \mathrm{kp}=0.25, \\
& \mathrm{kad}=0,06, k S=0,5, \mathrm{c}=0,6, \mathrm{p}=10, \quad \mathrm{z}=0.01, \\
& S e=180, \quad q y=50 .
\end{aligned}
$$

The following solution of an optimising problem has been discovered.

$$
\left(\begin{array}{c}
y m_{-} o p t \\
\text { p_opt } \\
\text { Rm0_opt } \\
\text { Sm_opt } \\
Z_{-} \text {opt }
\end{array}\right)=\left(\begin{array}{c}
6,16 \\
48,36 \\
76,19 \\
50,05 \\
50,9
\end{array}\right)
$$

$F_{T}\left(y m_{-} o p t, p \_o p t, R m_{-} o p t, S m_{-} o p t, Z_{-} \_p t\right)=16727$.

Let's become clear a reason of an optimality of a solution (22), (23). Key parameter defining full profit $F_{T}$ is capacity $y m$. Let $y m<y m_{-} o p t$, for example $y m=6,0$, remaining parametres are defined under the formula (22). Then calculation gives value $F_{T}=16056$. It is less than outcome of an optimum solution (23). Let $y m>y m_{-} o p t$, for example $y m=6,26$. Now calculation gives value $F_{T}=1418$. It is much less than 
optimum solution. Fig. 3 illustrates a reason of such reduction.

$S_{i}$ - current level of the goods in a warehouse;

$\mathrm{Sm}$ - maximum level of the goods in a warehouse.

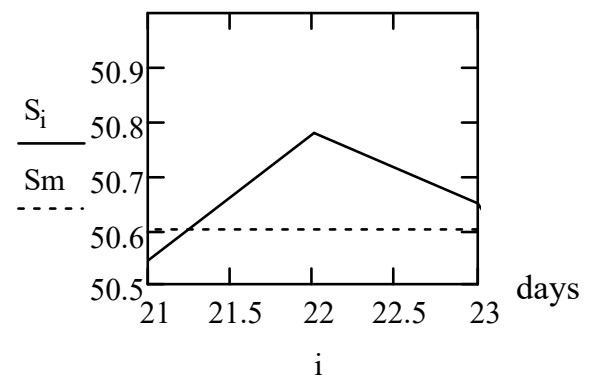

Fig. 3. Behavior of level of the goods in a wholesale warehouse at $y m=6,26$.

From Fig. 3 it is visible that at phase 21 "penal sanctions" come into effect. Overbillings of a wholesale warehouse can be avoided if more rigid restrictions on capacity in the formula (7) to superimpose, having reduced factor $q S$ from value 0,88 to 0,87 . Thus for $y m=6,26$, the value $F_{T}=16426$ has been received. It also is less than best value (24).

Above the problem only concerning a capacity modification has been investigated. However, there is still a possibility of a scale modification of all parameters. Let the parameter is factor defining scale transformation of all parameters of the LS: $X^{*}=q m \cdot X$ where $X$ is any of parametres in the left part a relation (22). Then it is possible to present association of economic outcome $F 1$ on scale factor in the form of table 2 .

Table 2. Association of the economic outcome on scale factor Costs for environmental protection and security.

\begin{tabular}{|c|c|c|}
\hline $\begin{array}{c}\text { Scale } \\
\text { factor, } q m\end{array}$ & $\begin{array}{c}\text { Costs for environmental } \\
\text { protection and security (min-max) }\end{array}$ & $\begin{array}{c}\text { Economic } \\
\text { outcome, } F 1\end{array}$ \\
\hline 0,95 & $723,35-2893$ & 14467 \\
\hline 1 & $836,35-3345$ & 16727 \\
\hline 1,004 & $819,7-3279$ & 16394 \\
\hline 1,008 & $56,85-227,4$ & 1137 \\
\hline
\end{tabular}

From table 2 it is visible that there is a certain scale of manufacture at which the economic outcome is maximum. It is obvious that this scale is set by an amount of potential customers of production $Q$.

Let's make the analysis of the received optimum solution (22), (23). For this purpose we will calculate dynamics of performances of the LS on the basis of a set of equations (1) - (8). Outcomes of calculations (at values of parameters (21)) are shown in Fig. 4 - Fig. 7.

Dynamics of basic rates of the LS is shown in Fig. 4. From figure it is visible that near to 100 periods all rates leave on value.

Equalization of rate of sales with rate of deliveries of the goods in retail trade (Fig. 4 see) results, according to the formula (4), to stabilization of quantity of the goods in the retail. It is visible from Fig. 5. $\mathrm{r}$ - rate of sales of the goods; so - rate of deliveries at the retail; $v$ - rate of production.

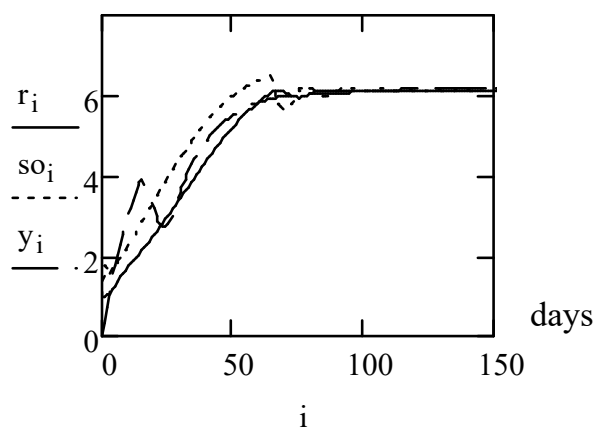

Fig. 4. Time dependence of basic rates of the LS.

$\mathrm{R}_{\mathrm{i}}$ - current level of the goods in retail;

$\mathrm{Rm} 0$ _opt - maximum level of the goods in retail.

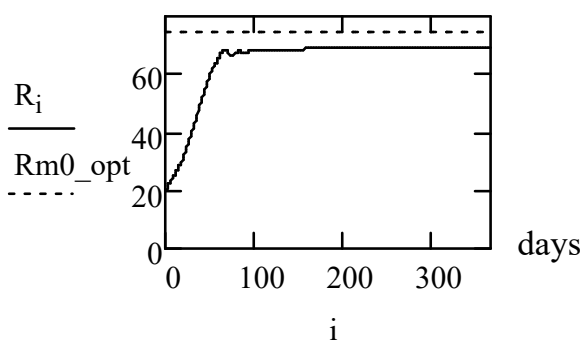

Fig. 5. Dynamics of level (quantity) of the goods in the retail.

$S_{i}$ - current level of the goods in a warehouse;

$\mathrm{Sm}-$ maximum level of the goods in a warehouse.

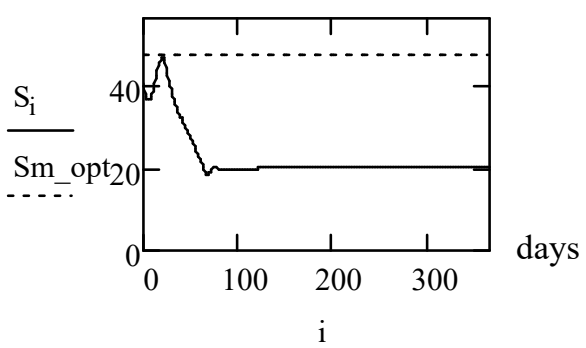

Fig. 6. Dynamics of level (quantity) of the goods in a wholesale warehouse.

It is important that goods level in the retail $R_{i}$ is close to the maximum capacity the retail (i.e. to contractual level $R m 0 \_o p t$ ), but in any period does not surpass a maximum level. That fact that $R_{i}$ is close to Rm0_opt, provides high rates of sales of the goods (see the formula (2)). This conclusion is quite clear.

Dynamics of level of the goods in a wholesale warehouse is shown in Fig. 6. That fact that goods level is stabilized near to the period 80 follows from Fig. 4 . By the period 80 rates of production $y_{i}$ and deliveries in the retail $s o_{i}$ become equal.

Let's notice that stabilization of level near to the maximum (contractual) stock of the goods in a network of retail trade which has been specified as a result of the 
solution of an optimizing task, is one of the basic conditions of effective work of the LS.

The sharp peak of stocks of the goods in a wholesale warehouse in the beginning of work which is observed in Fig. 6, can be explained with the help Fig. 7. From the formula (8) it is clear that during those periods, in which $y_{i}>s o_{i}$ stocks increase, and on the contrary.

so - rate of deliveries at retail;

$y$ - rate of production.

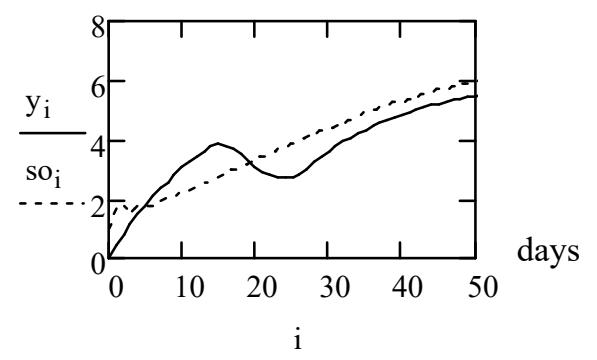

Fig. 7. Time dependence of rates of the goods imported on a wholesale warehouse $\left(y_{i}\right)$ and rates of the goods exported from a wholesale warehouse $\left(\mathrm{so}_{i}\right)$.

Fig. 7 shows stocks in a wholesale warehouse grow up to the period 20, then start to decrease. From Fig. 8 it is visible that goods stocks on hands at consumers are stabilized almost at the same level, as stocks in a wholesale warehouse.

Quantity of units of the goods on hands at consumers.

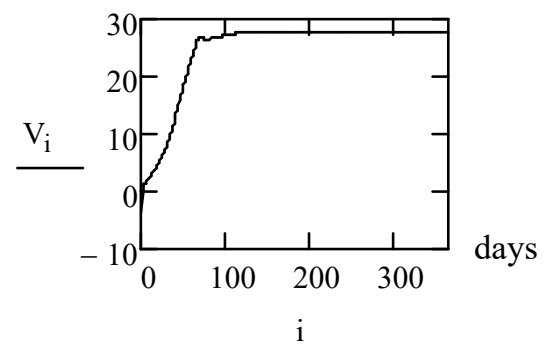

Fig. 8. Dynamics of level (quantity) of the goods on hands at consumers.

Fig. 9 shows dynamics of current profit of the enterprise for optimum solution. The current profit is negative work in initial stages. Such behavior of current profit is characteristic for an initial stage of work of any project. To understand why negative values of profit take place in our case, we will consider Fig. 10.

From the formula (9) it is visible that current value of profit of the enterprise basically is determined by a ratio of rates of production $\left(y_{i}\right)$ and rates of sales $\left(r_{i}\right)$. And sales of the goods bring the positive contribution, and goods production brings the negative contribution to profit (that is quite clear). In Fig. 10 the first 50 periods of work of the enterprise are shown. From drawing it is visible that during the first 20 periods (days) of work rate of production of the goods essentially exceeds rate of realization. It also leads to negative values of profit during these periods.

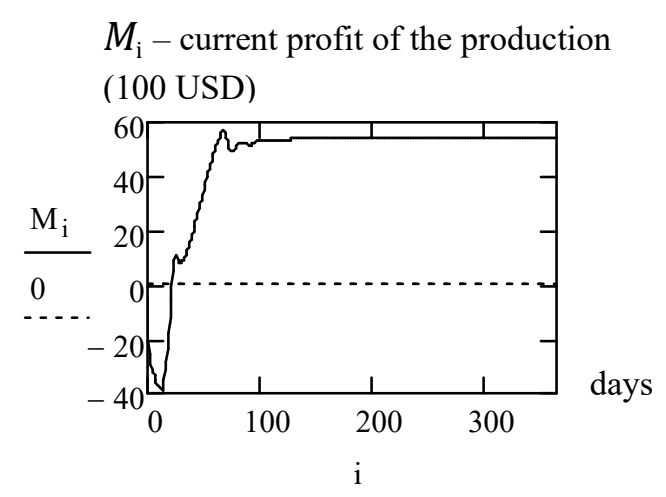

Fig. 9. Dynamics of current profit of the enterprise.

$\mathrm{r}$-rate of sales of the goods; $y$ - rate of production.

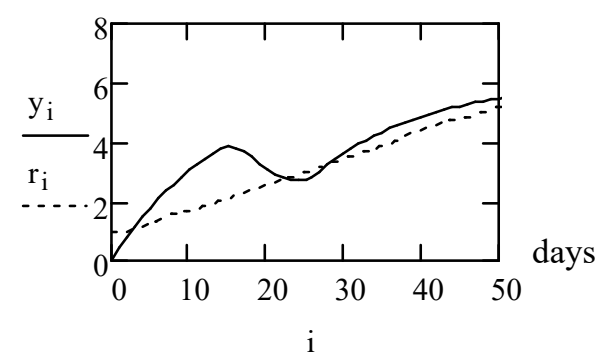

Fig. 10. Time dependence of rates of production $\left(y_{i}\right)$ and rates of sales $\left(r_{i}\right)$.

\section{Co-optimization of a warehouse of finished goods and a retail trade network}

The crucial role in logistics is played by storage facilities. Raw, having reached productions it is transformed to semi-finished products, and then in finished goods. Then, in a warehouse the finished goods are transformed to stocks or the collected customer orders. Customer orders, in turn, are transformed by means of a retail network of trade to money funds when there are at the end user.

At development of the project of logistic system of the enterprise, capacity and goods price can be set in advance (i.e. are exogenous parameters). Thus, the designing task will be reduced to an optimum choice of volumes of a wholesale warehouse and a retail trade network.

Statement of an optimizing task is a similar task (20) but with smaller quantity of variation parameters:

$$
F_{T}(R m, S m)=\sum_{i=1}^{T} M_{i} \rightarrow \max .
$$

Optimizing task (24) it is solved at such values of parameters:

$R m=56, q y=100, \mathrm{Q}=1000, \quad \mathrm{n}=0.00005$,
$\mathrm{k} 1=0.33, \quad k 2=0,01, \quad S o=50, \quad S m=103$,
$R o=40, \quad n 1=0,1, \quad q S=0,88, \quad \mathrm{kp}=0.25$,
$\mathrm{kad}=0,06, \quad k S=0,5, \mathrm{c}=0,6, \mathrm{p}=10, \mathrm{z}=0.05$, 
$S e=180, q y=50$.

The solution of an optimizing task (24) is the such:

$$
\begin{array}{r}
\left(\begin{array}{c}
R m 0_{\text {opt }} \\
S m_{\text {opt }}
\end{array}\right)=\left(\begin{array}{c}
64,7 \\
125,8
\end{array}\right), \\
F 1\left(R m 0_{\text {opt }}, S m_{\text {opt }}\right)=15717 .
\end{array}
$$

Consider dynamics of the basic economic characteristics for received solution. We will consider only initial stages before stabilization of counted characteristics. Fig. 11 shows that all rates become equal by 70 period of work of the enterprise.

$\mathrm{r}$-rate of sales of the goods;

so - rate of deliveries at retail;

$y$-rate of production.

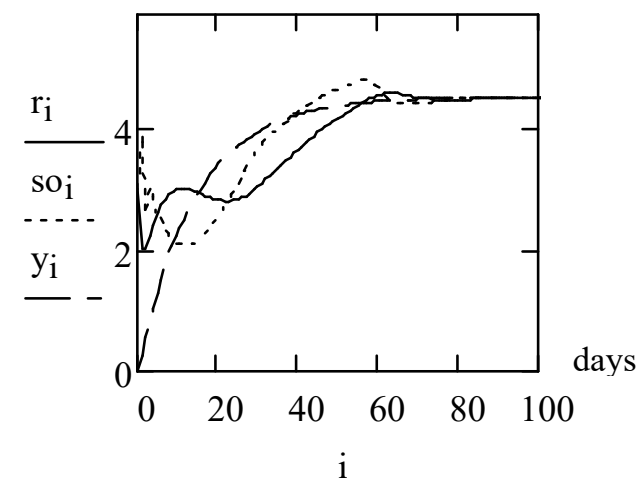

Fig. 11. Dynamics of the basic rates for optimum solution which is described by the formula (27).

That fact that rates become equal among themselves means stable work of LS. If it did not occur, the LS simply could not function as in this case would take a place or overflow of some storage facilities, or the goods stock was settled on some links of the LS. Fig. 12 shows dynamics of a stock of the goods in retail. We assume that in an initial stage retail trade is provided by a commodity output in number of 40 units and in a wholesale warehouse the finished goods stock constitutes 50 units.

$\mathrm{R}_{\mathrm{i}}$ - current level of the goods in retail;

$\mathrm{Rm} 0$ - the maximum level of the goods in retail.

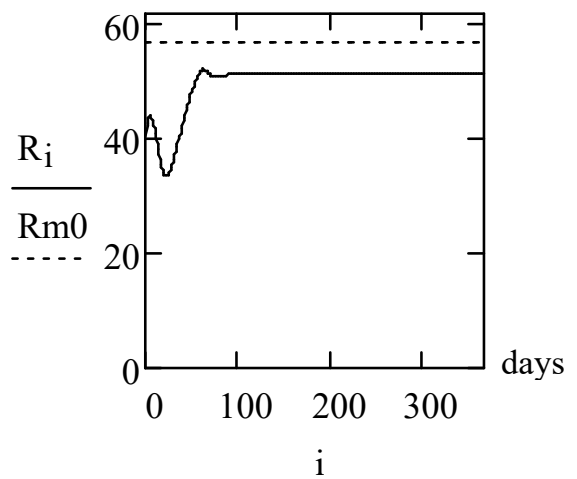

Fig. 12. Time dependence of a stock of the goods in retail.
Initial value of capacity it is considered equal to zero. These assumptions explain ratios of rates shown in Fig. 11 in work initial stages.

Fig. 13 shows dynamics of a stock of the goods at a wholesale warehouse.

$S_{i}$ - current level of the goods in a warehouse;

$\mathrm{Sm}$ - the maximum level of the goods in a warehouse.

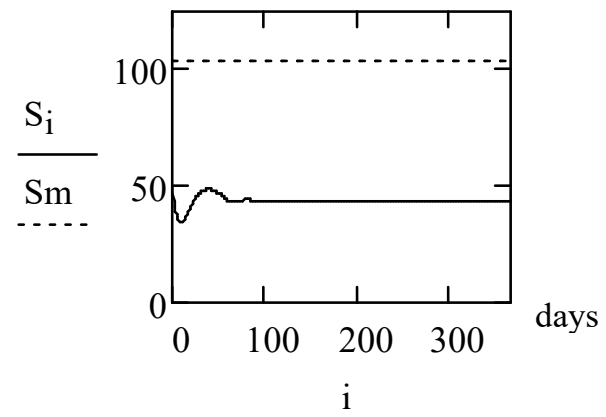

Fig. 13. Time dependence of a stock of the goods in a wholesale warehouse.

Fig. 14 explains behavior of a stock of the goods in a wholesale warehouse.

$$
\begin{aligned}
& \text { so - rate of deliveries at retail; } \\
& y \text { - rate of production. }
\end{aligned}
$$

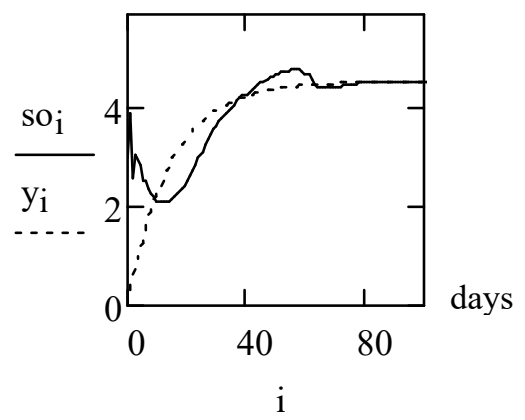

Fig. 14. Dynamics of the basic rates for optimum solution which is described by the formula (26).

Deliveries at retail during the first 8 periods reduce stocks in a wholesale warehouse because production has not time to recover them. Further to 30 periods deliveries in a wholesale warehouse from a production link dominate.

Fig. 15 shows dynamics of net profit of the enterprise for optimum solution which is described by the formula (26).

In a work initial stage considerable decrease is observed has beaten. Availability of such period characteristic is typical for any new project.

From the formula (9) it follows that the basic contribution to current profit of the enterprise is determined by a ratio of rate of sales $r_{i}$ and rate of production $y_{i}$. Fig. 16 explains dynamics of net profit of the enterprise shown in Fig. 15. 
Fig. 16 shows that at 100 periods the rate of sales becomes equal to the rate of manufacture; it leads to the stabilization of current profit. It is visible from Fig. 15.

$M_{\mathrm{i}}-$ current profit of the production (100 USD)

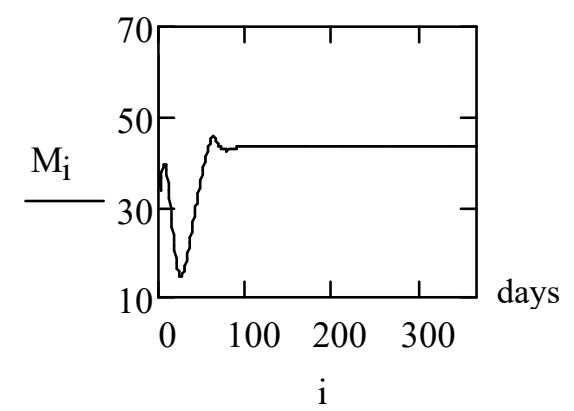

Fig. 15. Dynamics of net profit for optimum solution, which is described by the formula (26).

// $\quad \mathrm{r}$-rate of sales of the goods;

$y$-rate of production.

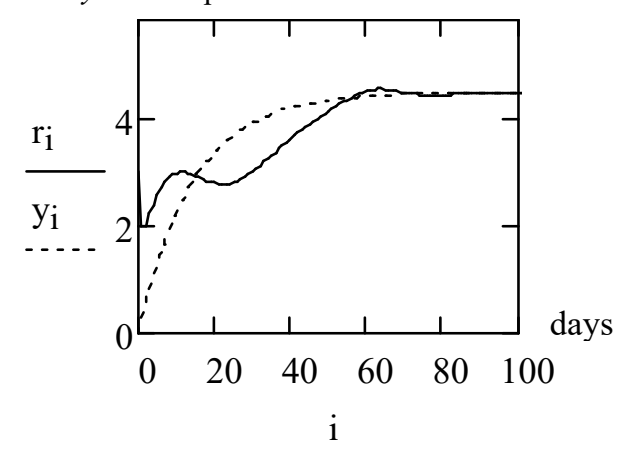

Fig. 16. Dynamics of the basic rates for optimum solution which is described by the formula (26).

\section{Conclusions}

The model of LS of the enterprise is developed. The offered model allows constituting the plan of capital investments for the new project. It is necessary to notice that plan development of investments is possible at detailed determination of characteristics of the project.

The developed model allows executing optimization of all key parameters of LS of the new project under conditions when the project budget is limited. The offered technique of optimization has allowed to specify values of all key parameters of LS of the new project taking into account budgetary restrictions, and also to calculate parameters of an advertising campaign and to specify enterprise price policy. Computations executed at set parameters of the LS have shown that from the complete budget of the project of $82,4 \%$ should be spent for the creation of capacities and the others of $17,6 \%$ on the creation of a network of retail trade.

Thus, the model of LS (1) - (9) allows to execute calculation of time dependence of all basic characteristics of LS that allows to manage all processes.

\section{References}

1. C. Kogler, P. Rauch, Discrete event simulation of multimodal and unimodal transportation in the wood supply chain: a literature review. SF 52, 4 (2018)

2. S. Lim, X. Jin, J. Srai, Consumer-driven ecommerce. IJPDLM 48, 3 (2018)

3. R. Manzini, R. Gamberini, Design, Management and Control of Logistic Distribution Systems (2008). doi:10.5772/5347

4. Y. Wei, T. Choi, Mean-variance analysis of supply chains under wholesale pricing and profit sharing schemes. EJOR 204, 2 (2010)

5. X. Li, Operations Management of Logistics and Supply Chain: Issues and Directions. DDNS, 701938 (2014)

6. N. Bostel, P. Dejax, Z. Lu, The Design, Planning, and Optimization of Reverse Logistics Networks, in Logistics Systems: Design and Optimization, ed. by A. Langevin, D. Riopel (Springer, Boston, 2005)

7. S. Melnyk, R. Narasimhan, H. DeCampos, Supply chain design: issues, challenges, frameworks and solutions. IJPR 52, 7 (2014)

8. L. Sosunova, S. Noskov, I. Goryacheva, N. Astafieva, S. Kalashnikov, Improving the management technique of logistics planning in the supply chain. PPM 16, 3 (2018)

9. A. Langevin, D. Riopel (eds.), Logistics Systems: Design and Optimization (2005). doi:10.1007/b106452

10. P. Bremer, Towards a reference model for the cold chain. IJLM 29, 3 (2018)

11. J. Siderska, Application of tecnomatix plant simulation for modeling production and logistics processes. BME 14, 1 (2016)

12. A. Gorsky, I. Kolpakova, B. Lokshin, Dynamic model of the production, storage and marketing of everyday goods. BRAS, TCS, 1 (1998)

13. Yu.V. Sherstennikov, T.M. Rudyanova, Modeling of mechanisms of influence on the pace of sales of enterprise products. APE 1 (2014) 